The actual frequency of offspring derived from each mating is given on the left of the table; the expected proportions in the more complex cases being given above the actual findings in parenthesis. The matings were made and the offspring examined in major part at the New Hampshire Agricultural Experiment Station and in minor part at the Station for Experimental Evolution. The latter station was able to contribute especially to the results of later generations. For horned females, Dorsets were used; for horned males Rambouillets, Dorsets and the Scottish 4-horned race. As hornless races the Downs were chiefly employed. It is not our purpose now to give complete details, as the experiments are being continued and full data will be deferred until the publication of our final report.

The results of the table accord very closely with expectation, so that we are justified in concluding that an explanation of the results like that we offer is the correct one. By our formula, then, the case of inheritance of horns in sheep is brought quite into line with that of other sex-limited characters, its peculiarities being due to an inhibitor of horn development that is carried in the sex-chromosome.

\section{LITERATURE CITED}

Bateson, W., 1909, “Mendel's Principles of Heredity," Cambridge, Eng., University Press.

Castle, W. E., 1911, "Heredity in Relation to Evolution and Animal Breeding,' New York, Appleton.

Guyer, M. F., 1910, "Accessory Chromosomes in Man," Biol. Bull., XIX., 219-234, Pl. I.

Wood, T. B., 1905, "Note on the Inheritance of Horns and Face Color in Sheep," Jour. Agric. Sci., I., 364, 365, Pl. IV.

$$
\begin{aligned}
& \text { T. R. Arkell, } \\
& \text { C. B. Davenport }
\end{aligned}
$$

DURHAM, N. H., Cold Spring Harbor, N. Y., January 29, 1912

THE "STOMACH STONES" OF REPTILES

Gastroliths have been known to occur, mingled with the remains of extinct reptiles, for many years and much attention has been called to them in the pages of Science and elsewhere, especially by Mudge, Seeley, Williston, Eastman, Wieland and Brown. Interesting parallels have been cited among several living vertebrates. There has been some contention that the stones were taken for the purpose of a "gastric mill," but they were in part at least accidental. There seems to be some evidence for the conclusion that the plesiosaurs, at least, selected stones for this purpose, though this may have been more accidental than we think. Recently there has been brought to my attention by Mr. Edward Taylor, of the University of Kansas, an interesting case of stone swallowing by a lizard, Phrynosoma cornutum Harlan. Only a single specimen is at hand for the data, but it is of sufficient interest in connection with identical habits among fossil reptiles to be recorded. The horned "toad" in question is a very large adult female collected by the late Dr. F. H. Snow in the Magdalen Mountains of New Mexico. In the stomach were twenty large, somewhat abraded stones of a rock which resembled lava. Some of the stones are very large, for the size of the animal, measuring nearly a third of an inch in diameter. There were also in the stomach about 200 of the large red ants, of an undetermined species, which make the large mounds so common to the western traveler. The animal had undoubtedly picked up the stones with the ants from the top of the mound and the association is probably accidental. That they served the purpose of a "gastric mill" once inside the digestive canal can not be doubted, whether the animal willed or no.

In this connection it may be of interest to the readers of these pages to call attention to some large Cretaceous sharks which have, within the past few months, been received at the University of Kansas Museum. In one specimen, consisting almost entirely of scattered vertebral cartilages, there are associated many hundreds of greatly abraded, very smooth and polished stones of white and black quartzite. That they belong with the shark can not be doubted on account of the 
association. The pebbles resemble to a great extent those figured by Dr. Williston some years ago as occurring with a pleisosaur. Another, nearly complete skeleton of a large shark, Isurus mantelli Ag., has preserved the larger part of the cranial cartilages. The sharks will shortly be described in detail and further reference need not be made to them here.

\section{The UNIVERsity of Kansas, January 26, 1912 \\ THE WASHINGTON MEETING OF THE AMERICAN CHEMICAL SOCIETY ${ }^{1}$}

THE meetings of the society were held from Wednesday, December 27, to Saturday, December 30 .

On Wednesday morning four papers were presented in joint session of the Section of Chemical Education and the Division of Physical and Inorganic Chemistry:

A. A. Noyes (chairman): The Teaching of Physical Chemistry.

W. D. BANCrofr: Physical Chemistry in the Introductory Course.

In the introductory course we should include: gas law; boiling-point curve; solubility; a brief statement of the dissociation theory; qualitative mass law, and qualitative catalysis. We should exclude: quantitative mass law; dilution law; solubility product, and reaction velocity. I am doubtful about electrolysis and osmotic pressure; but I should include the former and exclude the latter.

H. C. Jones: The Introduction of Physical Chemical Conceptions in the Early Stages of the Teaching of General Chemistry.

J. Howard Mathews: Some Applioations of Color Photography in the Teaching of Physical Chemistry. (Illustrated.)

The theory and manipulations of the "screenplate" processes of color photography were described briefly. Numerous scientific applications of color photography were pointed out, and each application was illustrated by color photographs thrown on the screen. The process has been found to be exceedingly useful in photographing inter-

${ }^{1}$ Most of these papers will be published in the Journal of the American Chemical Society or in the Journal of Industrial and Engineering Chemistry. ference figures and in recording the interference colors observed when certain erystals are viewed in polarized light. In many of the slides illustrating the latter, selenite plates were used to produce backgrounds of strong contrast and brilliant color. Photographs of "thin-sections" of various rocks showing their characteristic appearance in polarized light were also shown. The process has been found to be particularly well adapted to the projection of spectrum charts, etc., in colors. The absorption bands of chlorophyll were photographed directly in the spectroscope and a fairly accurate record obtained. Pure spectrum colors are not truly rendered by the process, since the color is always dependent on the dyes used to color the starch grains. However, an attempt to photograph the fluorescence of solutions of fluorescein met with considerable success.

The following three papers were presented in general meeting on Wednesday afternoon:

President Frankforter (Section C): The Resins and their Chemical Relations to the Terpenes.

To be published in Scrence.

H. P. TALBot (chairman Division of Physical and Inorganic Chemistry): Privileges and Responsibilities of the Chemical Analyst.

A. L. VoGe: Ostwald's Proposed International Institute of Chemistry (chiefly bibliography and library practise).

On Thursday evening two addresses were given in general session:

AleXANDER SMith (president American Chemical Society): An Early Physical Chemist.

Published in the issue of ScIENCE for February 1. FRANK B. KeNDRICK and H. E. HowE: Lantern Experiments on Reactions in Heterogeneous Systems.

A series of lantern illustrations of the effect of temperature, pressure, concentration, surface, osmotic pressure, etc., on reactions in heterogeneous systems. Several adaptations of a Bausch and Lomb balopticon were described, including a modification of the Töpler "Schlieren" apparatus for projection and the use of the lantern as a photographic camera.

On Friday a symposium on Mineral Waters was held before the Division of Industrial Chemists and Chemical Engineers. Titles of papers presented before this important symposium were published in SCIENCE of January 12. The papers themselves together with the voluminous discussion will be featured in the March issue of the Journal of Industrial and Engineering Chemistry. 